\title{
Comparison of Thermal Performance Equations in Describing Temperature- Dependent Developmental Rates of Insects: (I) Empirical Models
}

\section{Authors: Pei-Jian Shi, Gadi V.P. Reddy, Lei Chen, \& Feng $\mathrm{Ge}$}

This is a pre-copyedited, author-produced PDF of an article accepted for publication in Annals of the Entomological Society of America following peer review. The version of record [insert complete citation information here] is available online at: https://dx.doi.org/10.1093/aesa/sav121

Shi, Pei-Jian , Gadi V. P. Reddy, Lei Chen, and Feng Ge. "Comparison of Thermal Performance Equations in Describing Temperature-Dependent Developmental Rates of Insects: (I) Empirical Models." Annals of the Entomological Society of America 109, no. 2 (December 2015): 211-215. DOI: 10.1093/aesa/sav121.

Made available through Montana State University's ScholarWorks scholarworks. montana.edu 


\title{
Comparison of Thermal Performance Equations in Describing Temperature-Dependent Developmental Rates of Insects: (I) Empirical Models
}

\author{
Pei-Jian Shi, ${ }^{1}$ Gadi V. P. Reddy, ${ }^{2,3}$ Lei Chen, ${ }^{4}$ and Feng Ge ${ }^{5}$ \\ ${ }^{1}$ Co-Innovation Centre for Sustainable Forestry in Southern China, Bamboo Research Institute, Nanjing Forestry University, \\ Nanjing 210037, China (peijianshi@gmail.com), ${ }^{2}$ Montana State University, Western Triangle Ag Research Center, 9546 Old Shelby

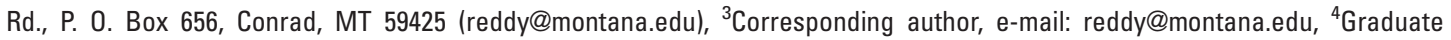 \\ School of Environmental Science, Hokkaido University, N19W8, Sapporo 060-0819, Japan (lei-chen1029@eis.hokudai.ac.jp), and \\ ${ }^{5}$ State Key Laboratory of Integrated Management of Pest Insects and Rodents, Institute of Zoology, Chinese Academy of \\ Sciences, Beijing 100101, China (gef@ioz.ac.cn)
}

\begin{abstract}
Temperature greatly affects the developmental duration of insects at their different stages, and many mathematical models exist for describing their temperature-dependent developmental rates. It is important to choose a suitable model to predict outbreaks of pest insects under climate change. However, previous comparisons among these models were usually based on a single species. In the present study, we compared the six nonlinear models (the Briére-1, Briére-2, Lactin, Performance-2, beta, and Ratkowsky models) based on the goodness of fit and the trade-off between the model's goodness of fit and structural complexity, using 10 temperaturedependent developmental rate datasets on insects to make the conclusions general. We found that the square root model (i.e., the Ratkowsky model) fitted all datasets well, and the curve shape produced by this model also approximates the curve shape of thermodynamically based mathematical models. The square root model was originally derived to be applicable to the growth rates of bacteria, and until now it has been generally ignored in entomology. We were mainly concerned with the predicted results obtained by using this model on observations of temperature-dependent developmental rates. We found that the square root model described well the pooled developmental rates in the low-, mid-, and high-temperature ranges, and we believe that it merits wider use in entomology.
\end{abstract}

Key words: goodness of fit, nonlinear, pest outbreak, square root model, structural complexity

Evidence has demonstrated that temperature has a significant influence on the developmental rate of insects (Uvarov 1931, Campbell et al. 1974). Under global climate change, pest outbreaks exhibit more complex dynamics and become more difficult to be predicted. To predict the developmental duration of important agricultural and forest pest insects exposed to different temperatures, many mathematical models have been proposed (e.g., Logan et al. 1976; Sharpe and DeMichele 1977; Schoolfield et al. 1981; Wang et al. 1982; Lactin et al. 1995; Brière et al. 1999; Ikemoto 2008; Shi et al. 2011; Régnière et al. 2012; Wang et al. 2013). These models have also been tried in the study of the effect of temperature on the growth rate of ectotherms (e.g., insects, mites, spiders, crabs, shrimps, fishes). Yin et al. (1995) proposed a beta function to reflect the effect of temperature on the developmental rate of crops. Ratkowsky et al. (1983) proposed a square root model to predict the effect of temperature on the growth rate of bacterial cultures. However, the latter two models have received little attention in entomological investigations. The previous studies in entomological research frequently compared the Logan, Lactin, and Briére models using a single species. From different studies, the conclusion as to which was the best model was usually different. In addition, the majority of previous studies used small sample sizes ranging from five to eight temperatures, which made the estimates of the parameters of the nonlinear models less precise.

In the present study, we chose several nonlinear models and data of temperature-dependent developmental rate with large sample sizes to examine the models' trade-off between goodness of fit and structural complexity. We attempted to find a general model that could well describe the majority of datasets on temperaturedependent developmental rates of insects. This work is also motivated by the studies of ontogenetic growth equation for animals and plants. A beta sigmoid growth equation obtained from the integral of the beta function has showed better fitting flexibility than some traditional growth models such as the exponential, Gompertz, 
Logistic, and von Bertalanffy models (Yin et al. 2003, Voorend et al. 2014, Shi et al. 2016). Thus, it is valuable to further compare the existing temperature-dependent developmental or growth models to find a better model than the beta function. Then we can obtain more new candidate ontogenetic growth models by using the integral form for the developmental or growth equation.

\section{Materials and Methods}

\section{Data}

Ten datasets of temperature-dependent developmental rates of insects were chosen (among which Sample 2 is a predatory mite, not an insect species). Table 1 lists the studied species, developmental stages, sample sizes, and data sources. We also compared the fitted results by using the mean and raw data of developmental rates of female fruit flies (Drosophila buzzatii Patterson \& Wheeler; i.e., Sample 10).

\section{Models}

In the present study, we used a total of six nonlinear models that all have the "conceptual" lower and upper developmental thresholds $\left(T_{1}\right.$ and $\left.T_{2}\right)$ at which developmental rates equal zero.

(i) Briére-1 equation (Brière et al. 1999):

$$
r=a T\left(T-T_{1}\right)\left(T_{2}-T\right)^{1 / 2}
$$

Here, $r$ represents developmental rate at temperature $T ; a$ is a constant; $T_{1}$ and $T_{2}$ represent "conceptual" lower and upper developmental thresholds at which developmental rates equal zero.

(ii) Briére-2 equation (Brière et al. 1999):

$$
r=a T\left(T-T_{1}\right)\left(T_{2}-T\right)^{1 / b}
$$

Here, the parameters are the same as those in the Briére- 1 equation except an additional parameter $b$, which makes the curve fitting more flexible. Then the Briére-1 equation is substantially a special case of the Briére- 2 equation when $b=2$.

(iii) Lactin equation (Lactin et al. 1995):

$$
r=\lambda+\mathrm{e}^{\rho T}-\mathrm{e}^{\rho T_{u}-\left(T_{u}-T\right) / \delta}
$$

Here, $\lambda, \rho, T_{\mathrm{u}}$, and $\delta$ are constants. And $T_{\mathrm{u}}$ is defined as the upper "lethal" temperature, which is higher than the "conceptual" upper developmental threshold (Lactin et al. 1995). In the Lactin equation, there are no $T_{1}$ and $T_{2}$ parameters. However, the curve produced by the Lactin equation has two intersections with the $\mathrm{X}$-axis (i.e., Temperature-axis). We can obtain $T_{1}$ and $T_{2}$ by a numerical method.

(iv) Performance-2 equation (Shi et al. 2011, Wang et al. 2013):

$$
r=c\left(T-T_{1}\right)\left(1-e^{K\left(T-T_{2}\right)}\right)
$$

Here, $c$ and $K$ are constants. This equation supersedes the Performance-1 equation (Wang et al. 2013), which has more parameters and produces a very similar curve shape to the Performance-2 equation.

(v) Beta equation (Yin et al. 1995, 2003; Shi et al. 2016):

$$
r=r_{\mathrm{m}}\left(\frac{T_{2}-T}{T_{2}-T_{\mathrm{m}}}\right)\left(\frac{T-T_{1}}{T_{\mathrm{m}}-T_{1}}\right)^{\frac{T_{\mathrm{m}}-T_{1}}{T_{2}-T_{m}}}
$$

Here, $r_{\mathrm{m}}$ represents the maximal developmental rate at temperature $T_{\mathrm{m}}$. Note: all parameters in the beta equation have clear meanings.

(vi) Ratkowsky equation (Ratkowsky et al. 1983):

$$
\sqrt{r}=c\left(T-T_{1}\right)\left(1-e^{K\left(T-T_{2}\right)}\right)
$$

This equation looks like the Performance-2 equation except there is a square root of $r$ in the leaf-hand side of equation. Thus, this equation is often called the square root equation.

\section{Model Evaluation}

In order to compare the goodness of fit and the trade-off between model's goodness of fit and structural complexity among these six nonlinear models, we used the residual sum of squares (RSS), coefficient of determination $\left(R^{2}\right)$, adjusted coefficient of determination $\left(R^{2}\right.$ adj $)$, root mean square error (RMSE), and corrected Akaike information criterion $\left(\mathrm{AIC}_{\mathrm{c}}\right)$.

$$
\mathrm{RSS}=\sum_{i=1}^{n}\left(r_{i}-\hat{r}_{i}\right)^{2}
$$

\begin{tabular}{|c|c|c|c|c|c|}
\hline \multicolumn{2}{|c|}{ Sample Species } & \multirow{2}{*}{$\begin{array}{l}\text { Order: Family } \\
\text { Lepidoptera: Noctuidae }\end{array}$} & \multirow{2}{*}{$\begin{array}{l}\text { Developmental stage } \\
\text { Pupa }\end{array}$} & \multicolumn{2}{|c|}{ Sample size Source } \\
\hline 1 & Helicoverpa armigera Hübner & & & 23 & Wu et al. (2009) \\
\hline 2 & Kampimodromus aberrans Oudemans & Acari: Phytoseiidae & Egg + larva +1 st-2nd nymphs & 9 & Broufas et al. (2007) \\
\hline 3 & Toxorbyynchites brecipalpis Theobald & Diptera: Culicidae & Egg & 19 & Trpis (1972) \\
\hline 4 & Bactrocera dorsalis Hendel & Diptera: Tephritidae & Egg & 19 & Messenger and Flitters (1958) \\
\hline 5 & Aedes aegypti $\mathrm{L}$. & Diptera: Culicidae & Larva & 15 & Gilpin and McClelland (1979) \\
\hline 6 & Bemisia tabaci (B-biotype) Gennadius & Hemiptera: Aleyrodidae & From egg to adult & 7 & Xiang et al. (2007) \\
\hline 7 & Lipaphis erysimi Kaltenbach & Hemiptera: Aphididae & From egg to adult & 12 & Liu and Meng (2000) \\
\hline 8 & Myzus persicae Sulzer & Hemiptera: Aphididae & From egg to adult & 11 & Liu and Meng (1999) \\
\hline 9 & Epilachna varivestis Mulsant & Coleoptera: Coccinellidae & e Larva & 8 & Shirai and Yara (2001) \\
\hline 10 & Drosophila buzzatii Patterson \& Wheeler & Diptera: Drosophilidae & From egg to adult & $9-1,204^{a}$ & de Jong (2010) \\
\hline
\end{tabular}

Here, $n$ represents the sample size; $r_{i}$ represents the $i$-th observation of developmental rate, and $r_{i}$ with a hat represents the predicted developmental rate.

$$
R^{2}=1-\frac{\sum_{i=1}^{n}\left(r_{i}-\hat{r}_{i}\right)^{2}}{\sum_{i=1}^{n}\left(r_{i}-\bar{r}_{i}\right)^{2}}
$$

Table 1. Ten datasets of temperature-dependent developmental rates of insects

${ }^{a} 9$ is the number of mean data of developmental rates, and 1,204 is the number of raw data of developmental rates. 
Here, $r_{i}$ with a dash represents the mean of the observed developmental rates. And the adjusted coefficient of determination is as follows:

$$
R_{\mathrm{adj}}^{2}=1-\frac{n-1}{n-p}\left(1-R^{2}\right)
$$

Here, $p$ represents the number of parameters in a nonlinear model including one for the error term. We also used the RMSE because the magnitude of the RMSE can be considered to be the "average deviation" between the observed data and the predicted values.

$$
\begin{aligned}
\mathrm{RMSE} & =\sqrt{\mathrm{RSS} /(n-p+1)} \\
\mathrm{AIC}_{\mathrm{c}} & =-2 L+2 p n /(n-p-1)
\end{aligned}
$$

where

$$
L=-\frac{n}{2} \ln \left(\frac{\mathrm{RSS}}{n}\right)
$$

We used RSS and $R^{2}$ as the indicators to evaluate the model's goodness of fit, and used $R_{\text {adj }}^{2}$, RMSE, and $\mathrm{AIC}_{\mathrm{c}}$ as the indicators to evaluate the trade-off between a model's goodness of fit and structural complexity.

The "nlinfit" function in Matlab 6.5 was used to carry out the nonlinear fitting. For robust estimation, "nlinfit" uses an iterative reweighted least squares algorithm. At every iteration, the robust weights are recalculated based on each observation's residual from the previous iteration. These weights downweight outliers, so that their influence on the fit is decreased. Iterations continue until the weights converge. We provided the Matlab procedures for carrying out the nonlinear fitting for a given dataset of temperaturedependent developmental rates (see Supp Material 1 [online only] for details).

\section{Results}

Supp Table 1 (see Supp Material 2 [online only] for details) shows the comparative results. From the viewpoint of a trade-off between the model's goodness of fit and structural complexity (based on the calculated $R_{\text {adj }}^{2}$ or RMSE or $\mathrm{AIC}_{\mathrm{c}}$ ), the Briére- 2 equation was better than the Briére-1 equation in five cases with larger sample size $(n>10)$, but the latter performed better for the datasets with smaller sample size $(n<10)$. However, the Briere-2 equation had a better goodness of fit than the Briére-1 equation for all datasets investigated. Because of an additional parameter, $b$, the Briére- 2 equation is more flexible in producing a curve shape. From Sample 10 with a small sample size of mean data, we found that the Briere- 1 equation obtained a better trade-off between the model's goodness of fit and structural complexity than the Briére- 2 equation; however, it is worse than the Briére-2 equation when using the raw data. Except for Samples 4 and 7, the Ratkowsky equation had a better goodness of fit than the Briére-2 equation for all other samples. It was also better than the Briére- 2 equation based on the calculated $R_{\text {adj }}^{2}$, RMSE, and $\mathrm{AIC}_{\mathrm{c}}$. Although the beta equation fitted the data of the observed developmental rates well, it was demonstrated to be no better than the Ratkowsky equation from the point of view of goodness of fit or from the trade-off between model's goodness of fit and structural complexity. We also found that the curve shape produced by the beta equation was more similar to that produced by the Ratkowsky equation, relative to the others. For the remaining two equations (i.e., the Lactin and Performance-2 equations), the goodness of fit or the trade-off between model's goodness of fit and structural complexity was worse than the Briere-2 equation or the Ratkowsky equation. The data showed that in the mid-temperature range, a perfect linear relationship between temperature and developmental rate did not exist. However, the Lactin and Performance-2 equations had assumed a very approximate linear relationship between them. Thus, they could not perform better than the others for most datasets.

The lower and upper developmental thresholds are a matter of interest to some investigators, because they want to know the predicted critical temperatures where insects stop developing. Traditionally, the linear fitting was used to calculate the lower developmental threshold by using the developmental rate data in the mid-temperature range. The intersection between the straight line and the X-axis is reckoned as the lower developmental threshold. For estimating the upper developmental threshold, the Logan, Briére, Lactin, and Performance equations are usually used. From the model's goodness of fit or the tradeoff between model's goodness of fit and structural complexity, the Lactin equation was better than the Performance-2 equation for each species investigated. The Briere- 1 and Briére- 2 equations provided an approximate estimate on the "conceptual" upper developmental threshold, but their estimates on the "conceptual" lower developmental threshold were lower than the estimates by using the Lactin and Performance- 2 equations. The beta and Ratkowsky equations described the effect of temperature on the developmental rates of insects in the mid-temperature range better than the Lactin and Performance-2 equations.

Supp Figs. 1-11 (see Supp Material 3 [online only] for details) visually exhibit the fitted results using these six nonlinear equations to 10 datasets. There are nine insect species and one mite species (i.e., Sample 2). Supp Figs. 10 and 11 (online only) described the same insect species (D. buzzatii), but with different sample sizes. Supp Fig. 10 (online only) used the mean data, whereas Supp Fig. 11 (online only) used the raw data. The open circles represent the observations of developmental rates, and the curves represent the predicted developmental rates based on different nonlinear models. For every species, the aforementioned six nonlinear models were used to fit the data of temperature-dependent developmental rates, respectively.

\section{Discussion}

As an empirical method, the predicted lower developmental threshold by using the linear equation in the mid-temperature range usually approximates its actual lower terminating temperature for development. However, the Briére-1, Briére-2, beta, and Ratkowsky equations only provide "conceptual" lower and upper developmental thresholds, and the estimates of these two extreme temperatures by these nonlinear equations do not accord with the actual observed threshold temperatures. Although the Lactin and Performance-2 equations can provide the approximate estimates to the actual developmental thresholds, these two equations cannot reflect an approximate exponential growth relationship between temperature and developmental rate in the low-temperature range (Uvarov 1931, Campbell et al. 1974). If the data of developmental rates at low temperatures are lacking, the Lactin and Performance- 2 can fit the data well (see Sample 6 in Supp Fig. 6 [online only]). However, these two equations cannot overall reflect the nonlinear relationship between temperature and pooled developmental rates in the low- and midtemperature ranges. We believe that these two nonlinear equations can do well on the condition that the data in the low-temperature range are lacking. Thus, we do not approve using the Lactin and Performance- 2 equations to fit the data including the developmental rates in the low-temperature range. The Briére-1 and Briére-2 

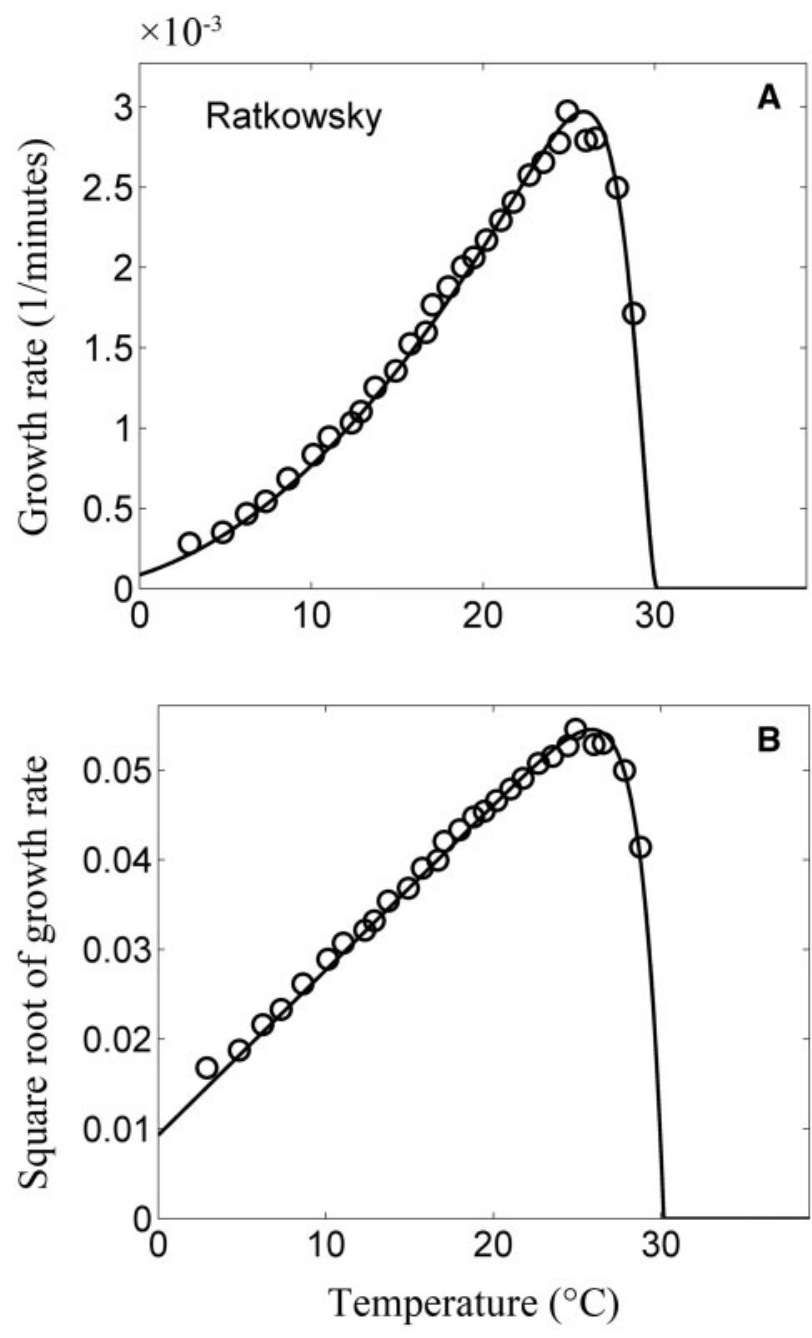

Fig. 1. Effect of temperature on the growth rate of $F$. hibernum. (A) Temperature-dependent growth rate. The small open circles represent the observed growth rates $(1 / \mathrm{min})$, and the curve represents the predicted growth rates at different temperatures. (B) Square root of growth rate.

equations also applied to many samples, but the latter was shown to be better than the former actually as a special case of the latter. We consider that the additional parameter (i.e., in the Briére- 2 equation) is justified, making data fitting more flexible. The Briére-2 equation was almost applicable to all samples investigated. For Sample 9, the last datum was intentionally excluded to check the predicting abilities of different models. We found that the Briére-2, Lactin, and Performance- 2 equations provided an impractical prediction for the developmental rate at the excluded temperature, whereas the beta and Ratkowsky equations provided acceptable predictions at this excluded temperature. In this case, we should approve the use of the Ratkowsky equation rather than the Briere- 2 equation. In fact, the curve shape produced by the Ratkowsky equation approximates that produced by the SSI or ROR models based on thermodynamic theories (Ikemoto 2008, Ikemoto et al. 2013, Ratkowsky et al. 2005, Corkrey et al. 2012). These two thermodynamic equations also predicted a slightly concave curve in the high-temperature range. In practice, it is impossible to observe reliable developmental rates at temperatures near the upper developmental threshold because of high mortality at these temperatures. Thus, it is difficult to determine which model is most reasonable in predicting developmental rates near the actual upper developmental threshold. However, we found that the degree of curvature of the Ratkowsky equation near the upper developmental threshold was very small when developmental rates in the high-temperature range exhibited a sharp drop with increased high temperatures (see Supp Figs. 1 and 4 [online only]). We also showed an example of growth rate of Flavobacterium hibernum McCammon, a lactose-utilizing bacterium from a freshwater Antarctic lake (Fig. 1; McCammon et al. 1988). In fact, the Ratkowsky equation has been demonstrated to apply to many other datasets of growth rates of bacteria (Ratkowsky et al. 2005), as that model was originally developed to describe the temperature dependence of bacterial growth. Schoolfield et al. (1981) consider that the temperature-dependent rate models are applicable to both developmental rate and growth rate of poikilotherms. The Logan model (Logan et al. 1976) is always used to describe the effect of temperature on the developmental rate of insects, and is also used for the growth rate of insects calculated from life table methods. Thus, it is feasible to introduce the Ratkowsky equation to the investigation of temperature-dependent developmental rate of insects, considering its good performance in fitting data.

In all the models, temperatures such as $T_{1}$ and $T_{2}$ should just be looked upon as mathematical symbols and not predictors of minimum or maximum temperatures of a range at which development can occur. For the square root model (i.e., the Ratkowsky model), Ratkowsky et al. have never maintained that these temperatures are anything more than notional (or notational) temperatures, and there is no organism on Planet Earth (bacterial, archaeal, eucaryotic) that we are aware of which can grow at temperatures approaching $T_{1}$ from above. That is, usually the true minimum observable temperature for growth is several degrees $\left({ }^{\circ} \mathrm{C}\right.$ or $\left.\mathrm{K}\right)$ above the notional minimum temperature. At the upper end of the temperature scale, the difference between the notional maximum temperature $T_{2}$ and the observable maximum temperature $T_{\max }$ may be much smaller than at the lower end (perhaps as small as $1^{\circ} \mathrm{C}$ ), so it is very difficult to get reliable data at this upper threshold temperature because of high mortality rates. Thus, we advocate that when using any of the six models, there should be no thoughts that these equations are doing anything more than possibly providing a good fit to existing data on temperature dependence of growth rate. The models simply do not incorporate a prediction of the range of temperature dependence.

\section{Supplementary Data}

Supplementary data are available at Annals of the Entomological Society of America online.

\section{Acknowledgments}

We are deeply grateful to Prof. David Ratkowsky (University of Tasmania, Australia) for providing invaluable comments on the early version of this study, and we also thank Prof. Gerdien de Jong (Utrecht University, The Netherlands) and Dr. Takaya Ikemoto (Teikyo University School of Medicine, Japan) for providing the partial data used in the present study. P.-J. Shi was supported by the National Natural Science Foundation for Young Scholars of China (31400348), the Priority Academic Program Development of Jiangsu Higher Education Institutions, and the Startup Foundation of Nanjing Forestry University (GXL038). F. Ge was supported by the National Natural Science Foundation of China (31221091) and the R\&D Special Foundation for Public Welfare Industry (Agriculture 201303019-05). 


\section{References Cited}

Brière, J.-F., P. Pracros, A.-Y. Le Roux, and J.-S. Pierre. 1999. A novel rate model of temperature-dependent development for arthropods. Environ. Entomol. 28: 22-29.

Broufas, G. D., M. L. Pappas, and D. S. Koveos. 2007. Development, survival, and reproduction of the predatory mite Kampimodromus aberrans (Acari: Phytoseiidae) at different constant temperatures. Environ. Entomol. 36: 657-665.

Campbell, A., B. D. Frazer, N. Gilbert, A. P. Gutierrez, and M. Mackauer. 1974. Temperature requirements of some aphids and their parasites. J. Appl. Ecol. 11: 431-438.

Corkrey, R., J. Olley, D. Ratkowsky, T. McMeekin, and T. Ross. 2012. Universality of thermodynamic constants governing biological growth rates. PLoS ONE 7: e32003.

de Jong, G. 2010. A biophysical interpretation of temperature-dependent body size in Drosophila aldrichi and D. buzzatii. J. Therm. Biol. 35: 85-99.

Gilpin, M. E., and G.A.H. McClelland. 1979. Systems analysis of the yellow fever mosquito Aedes aegypti. Fortschr. Zool. 25: 355-388.

Ikemoto, T. 2008. Tropical malaria does not mean hot environments. J. Med. Entomol. 45: 963-969.

Ikemoto, T., I. Kurahashi, and P.-J. Shi. 2013. Confidence interval of intrinsic optimum temperature estimated using thermodynamic SSI model. Insect Sci. 40: 240-248.

Lactin, D. J., N. J. Holliday, D. L. Johnson, and R. Craigen. 1995. Improved rate model of temperature-dependent development by arthropods. Environ. Entomol. 24: 68-75.

Liu, S., and X. Meng. 1999. Modelling development time of Myzus persicae (Hemiptera: Aphididae) at constant and natural temperatures. Bull. Entomol. Res. 89: 53-63.

Liu, S., and X. Meng. 2000. Modelling development time of Lipaphis erysimi (Hemiptera: Aphididae) at constant and natural temperatures. Bull. Entomol. Res. 90: 337-347.

Logan, J. A., D. J. Wollkind, S. C. Hoyt, and L. K. Tanigoshi. 1976. An analytic model for description of temperature dependent rate phenomena in arthropods. Environ. Entomol. 5: 1133-1140.

McCammon, S., B. Innes, J. Bowman, P. Franzmann, S. Dobson, P. Holloway, J. Skerratt, P. Nichols, and L. Rankin. 1998. Flavobacterium hibernum sp. nov., a lactose-utilizing bacterium from a freshwater Antarctic lake. Int. J. Syst. Bacteriol. 48: 1405-1412.

Messenger, P. S., and N. E. Flitters. 1958. Effect of constant temperature environments on the egg stage of three species of Hawaiian fruit flies. Ann. Entomol. Soc. Am. 51: 109-119.

Ratkowsky, D. A., R. K. Lowry, T. A. McMeekin, A. N. Stokes, and R. E. Chandler. 1983. Model for bacterial culture growth rate throughout the entire biokinetic temperature range. J. Bacteriol. 154: 1222-1226.
Ratkowsky, D. A., J. Olley, and T. Ross. 2005. Unifying temperature effects on the growth rate of bacteria and the stability of globular proteins. J. Theor. Biol. 233: 351-362.

Régnière, J., J. Powell, B. Bentz, and V. Nealis. 2012. Effects of temperature on development, survival and reproduction of insects: experimental design, data analysis and modeling. J. Insect Physiol. 58: 634-647.

Schoolfield, R. M., P.J.H. Sharpe, and C. E. Magnuson. 1981. Non-linear regression of biological temperature-dependent rate models based on absolute reaction-rate theory. J. Theor. Biol. 88: 719-731.

Sharpe, P.J.H., and D. W. DeMichele. 1977. Reaction kinetics of poikilotherm development. J. Theor. Biol. 64: 649-670.

Shi, P., F. Ge, Y. Sun, and C. Chen, 2011. A simple model for describing the effect of temperature on insect developmental rate. J. Asia-Pacific Entomol. 14: 15-20.

Shi, P., L. Chen, C. Hui, and H. D. Grissino-Mayer. 2016. Capture the time when plants reach their maximum body size by using the beta sigmoid growth equation. Ecol. Model. 320: 177-181.

Shirai, Y., and K. Yara. 2001. Potential distribution area of the Mexican bean beetle, Epilachna varivestis (Coleoptera: Coccinellidae) in Japan, estimated from its high-temperature tolerance. Appl. Entomol. Zool. 36: 409-417.

Trpis, M. 1972. Development and predatory behavior of Toxorhyynchites brecipalpis (Diptera: Culicidae) in relation to temperature. Environ. Entomol. 1: 537-546.

Uvarov, B. P. 1931. Insects and climate. Trans. Entomol. Soc. Lond. 79: 1-232.

Voorend, W., P. Lootens, H. Nelissen, I. Roldán-Ruiz, D. Inzé, and H. Muylle. 2014. LEAF-E: a tool to analyze grass leaf growth using function fitting. Plant Methods 10: 37. (doi:10.1186/1746-4811-10-37).

Wang, R.-S., Z.-X. Lan, and Y.-Q. Ding. 1982. Studies on mathematical models of the relationship between insect development and temperature. Acta Ecol. Sin. 2: 47-57.

Wang, L., P. Shi, C. Chen, and F. Xue. 2013. Effect of temperature on the development of Laodelphax striatellus (Homoptera: Delphacidae). J. Econ. Entomol. 106: 107-114.

Wu, K., P. Gong, and Y. Ruan. 2009. Estimating developmental rates of Helicoverpa armigera (Lepidoptera: Noctuidae) pupae at constant and alternating temperature by nonlinear models. Acta Entomol. Sin. 52: 640-650.

Xiang, Y., X. Guo, F. Zhang, Z. Li, and C. Luo. 2007. Effects of temperature and humidity on the development and reproduction of Bemisia tabaci (Homoptera: Aleyrodidae) Biotype B. Acta Agric. Boreali-Sin. 22: 152-156.

Yin, X., M. J. Kropff, G. McLaren, and R. M. Visperas. 1995. A nonlinear model for crop development as a function of temperature. Agric. For. Meteorol. 77: 1-16.

Yin, X., J. Goudriaan, E. A. Lantinga, J. Vos, and H. J. Spiertz. 2003. A flexible sigmoid function of determinate growth. Ann. Bot. 91: 361-371. 